\title{
Como se constrói uma universidade: a trajetória da UERJ na visão de seus reitores
}

\author{
Leonardo Faria Cazes*
}

\section{Introdução}

Efemérides são sempre oportunidades de rever o passado e fazer um balanço da trajetória percorrida até ali. Isso vale para indivíduos, grupos sociais e instituiçóes. No caso da Universidade do Estado do Rio de Janeiro (UERJ) não é diferente. Ao completar 70 anos em 2020, uma série de eventos e publicaçóes oficiais da universidade buscam dar conta do que se passou entre o momento de fundação e o presente atual. ${ }^{1}$ Estas celebraçôes, entretanto, não são neutras: pelo contrário, a reconstruçáo de um passado recente parte sempre das memórias dos sujeitos envolvidos, cujas demandas são atualizadas pelo presente (Pollak, 1989). Por outro lado, é impossível abarcar tudo que se passou ao longo de décadas. Há escolhas sobre o que deve ser narrado, o que deve ser lembrado, o que é digno de ser incluído numa "história oficial" da instituição - não cabe aqui fazer um juízo de valor destas escolhas institucionais, mas antes reconhecer simplesmente que elas existem.

* Mestre e doutorando em História pelo Programa de Pós-Graduação em História da Universidade Federal Fluminense (PPGH-UFF). Atualmente, desenvolve pesquisa sobre a rede de sociabilidade intelectual estabelecida entre professores da Universidade do Estado do Rio de Janeiro (UERJ) e militares da Escola de Comando e Estado-Maior do Exército (ECEME) e da Escola Superior de Guerra (ESG) durante a ditadura civil-militar brasileira, sob orientação da professora Samantha Viz Quadrat. E-mail: leocazes@ gmail.com.

1 Como parte das comemorações, a universidade produziu o livro "UERJ 70 anos: 1950-2020", coordenado pelo prof. Luís Reznik, da Faculdade de Formação de Professores (FFP/UERJ), além da exposição "ESQUELE7O", sobre a história da instituição, no Paço Imperial, centro do Rio de Janeiro. 
Todos esses dilemas presentes hoje também estavam presentes em 1980, quando a UERJ completou seus primeiros 30 anos, intensamente celebrados. $\mathrm{Na}$ ocasião, havia muito o que se comemorar. Quatro anos antes, a universidade tinha inaugurado os 12 prédios que compóem o pavilhão batizado de João Lyra Filho, reitor da UERJ entre 1967 e 1972, a concretização do projeto da "microuniversidade urbana" nas palavras de um de seus idealizadores, o professor Wilson Choeri (Pronta em... 1989). Era o momento, pois, de consolidação da universidade após quase duas décadas de luta pela construção do campus. $\mathrm{Na}$ ocasiāo, ocupava o posto de reitor o jurista Ney Cidade Palmeiro. As comemoraçóes pelos 30 anos da UERJ se estenderam por uma série de atividades realizadas entre os dias 6 e 18 de outubro daquele ano, com farta distribuição de medalhas, títulos honoríficos e homenagens a personalidades ligadas à instituição - como ex-professores, ex-diretores e ex-reitores - e aos Três Poderes do estado do Rio de Janeiro e da União. ${ }^{2}$ Contudo, a iniciativa que nos interessa é o lançamento do programa institucional Memória UERJ, que começa suas atividades entrevistando dois reitores cujos depoimentos serão analisados no presente artigo: Haroldo Lisboa da Cunha (1960-1967) e João Lyra Filho (1967-1972).

Lisboa da Cunha e Lyra Filho foram as duas principais lideranças do processo de reforma e expansão que a UERJ viveu nas décadas de 1960 e 1970. Ao assumir o cargo em 1960, o primeiro encontrou uma instituição que existia apenas no papel, pois estava fragmentada na cidade e na burocracia. Ao longo de sua gestão, o professor foi o responsável por capitanear a discussão sobre a localização do campus e a produção dos estudos e planos que forjaram a base para a reorganização da universidade. Já na gestáo de Lyra Filho, o projeto de construção do campus do Maracaná começou a sair do papel, passo fundamental para a materialização dos planos elaborados na gestão anterior, e sua engenharia administrativa e financeira teve papel fundamental ao permitir que a obra fosse tocada com recursos próprios.

Antes de nos debruçarmos sobre os depoimentos, porém, é preciso esclarecer o contexto político interno da UERJ em 1980. Naquele ano, completava-se duas décadas que o mesmo grupo político oriundo da antiga Faculdade de Filosofia, Ciências e Letras (FFCL) do Instituto La-Fayette - uma das quatro faculdades particulares encampadas em 1950 para a criação da então Universidade do Distrito Federal (UDF) - ocupava a reitoria. Dos cinco reitores da UERJ entre 1960 e 1980, quatro eram membros da congregação da FFCL no final da década

2 DELFOS. Rio de Janeiro, n. 19-20, 1979-1980. A Delfos era a revista da Associação dos Diplomados da FFCL. A coleção, apesar de incompleta, se encontra disponível na Biblioteca do Centro de Educação e Humanidades (CEH/A) da UEJ, no $12^{\circ}$ andar do Pavilhão João Lyra Filho, Campus Maracanã. 
de 1950 - Haroldo Lisboa da Cunha, João Lyra Filho, Oscar Accioly Tenório e Ney Cidade Palmeiro.

A chegada desse grupo à reitoria coincide com uma substantiva redistribuição interna do poder. A Lei $\mathrm{n}^{\circ}$ 930, de julho de 1959, retirou o poder de escolha dos diretores das faculdades das respectivas congregaçōes, controladas pelos seus catedráticos, e o concedeu ao reitor, que passou a nomear os diretores com a prévia autorização do prefeito do Distrito Federal. Ficou vedada também a reeleição para qualquer cargo eletivo na universidade, um expediente bastante comum que garantia a poucos catedráticos os postos de comando. Assim, as congregaçóes das faculdades perderam poder, mas esse não foi democratizado pela comunidade universitária. Antes, tratou-se de uma concentração de poderes na reitoria e no Conselho Universitário, duas instâncias que continuavam sendo controladas por um pequeno grupo de professores catedráticos (Mancebo, 1996).

Essa mudança é significativa porque, até então, a Universidade do Rio de Janeiro (URJ), como foi rebatizada em 1958, era uma universidade apenas no nome, já que as quatro faculdades fundadoras - FFCL, Faculdade de Direito do Rio de Janeiro, Faculdade de Ciências Médicas e Faculdade de Ciências Econômicas mantinham sua autonomia administrativa, pedagógica e financeira. Esse cenário só mudou em 1959, quando a Lei n 930 também autorizou a universidade "a incorporar ao seu patrimônio os bens pertencentes às unidades, nos limites do seu orçamento", além de prever que novas unidades incorporadas cederiam seus patrimônios à instituição. É importante destacar que essa legislação foi aprovada sob intensa pressão dos estudantes que lutavam pela gratuidade do ensino, tema que mobilizou o corpo discente ao longo dos anos 1950 (Mancebo, 1996).

A centralização dos poderes na reitoria e no Conselho Universitário era uma etapa indispensável para a consolidação da universidade, mas não suficiente. $\mathrm{O}$ desafio seguinte era superar a fragmentação administrativa e espacial que caracterizava a instituição e consistia num dos principais entraves à sua reestruturação. A universidade estava espraiada pela cidade, com suas unidades distribuídas pelos bairros da Tijuca (FFCL), Catete (Faculdade de Direito), Vila Isabel (Faculdade de Ciências Médicas) e Lapa (Faculdade de Ciências Econômicas). A Faculdade de Engenharia, criada em 1961, ocupou um prédio em São Cristóvão. A reitoria, por sua vez, primeiro ficou localizada no prédio da Faculdade de Ciências Médicas e depois ganhou uma sede própria num casarão em Laranjeiras.

Foi a esta tarefa de transformar a "federação" de faculdades isoladas física, administrativa e pedagogicamente numa verdadeira universidade integrada que se dedicou o grupo que chegou ao poder em 1960 com Haroldo Lisboa da Cunha - nesse mesmo ano a instituiçáo foi rebatizada novamente, de Universidade do 
Estado da Guanabara (UEG). Vinte anos depois, quando a UERJ 3 - nome que a universidade assumiu após a fusão em 1975 - completava 30 anos de fundação, essa missão estava concluída e a celebração do trintenário era um momento auspicioso para que os dirigentes envolvidos nessa empreitada lançassem um olhar sobre o passado e o que tinham construído até ali. Não à toa, é neste momento que o programa Memória UERJ é criado e escolhe como os seus dois primeiros entrevistados os ex-reitores Haroldo Lisboa da Cunha e João Lyra Filho.

Outro fator que deve ser levado em consideração ao se analisar a criação do Memória UERJ é o momento político que o Brasil vivia. Em 1980, o país vivia o processo de abertura política, com o retorno dos principais líderes de oposiçáo após a aprovação da Lei de Anistia no ano anterior. Os ventos da democracia que começavam a soprar com mais intensidade também atingiam a universidade e encontravam na reitoria um grupo que trabalhou muito próximo dos militares ao longo de toda ditadura, principalmente na formulação de políticas públicas na área de Educaçáo. A UERJ organizou e seus dirigentes participaram de seminários em 1965 e 1966 onde foram forjadas as bases do Projeto Rondon, e saiu da universidade a primeira turma que viajou pelo projeto, liderada pelo professor Omir Fontoura, em julho de 1967 (Amato, 2015). Houve também uma intensa circulação de docentes entre a universidade e as escolas superiores militares do Rio de Janeiro, como a Escola de Comando e Estado Maior do Exército (ECEME) e a Escola Superior de Guerra (ESG), como aponta Lerner (2013). O reitor João Lyra Filho fez parte do Grupo de Trabalho da Reforma Universitária (GTRU), montado pelo ministro da Educação Tarso Dutra em agosto de 1968, um dos embrióes da Reforma Universitária aprovada em novembro daquele ano (Fávero, 1991). Assim, a criação do programa Memória UERJ era uma forma de sedimentar uma memória sobre o caminho percorrido pela instituição até ali e garantir o lugar do grupo na história da universidade.

Antes de entrar na análise dos depoimentos de Lisboa da Cunha e Lyra Filho, é importante delinear certas características do Memória UERJ. Primeiro, o programa foi criado e é conduzido até hoje no âmbito do Centro de Tecnologia Educacional (CTE) da universidade, apesar da existência de um Núcleo de Memória, Informação e Documentação (MID), responsável por guardar e promover a memória institucional da UERJ. A iniciativa não foi conduzida como um programa de História Oral nos moldes daqueles desenvolvidos, por exemplo, pelo Centro de Documentação e Pesquisa de História Contemporânea do Brasil (CPDOC) da Fundação Getúlio Vargas (FGV), a partir da década de 1970. Se no caso do CPDOC/FGV havia o objetivo de introduzir no Brasil práticas de

3 A partir deste ponto, vamos nos referir à universidade apenas como UERJ. 
pesquisa, abordagens metodológicas e novos temas - como a História do Tempo Presente - que vinham ganhando força no exterior, em particular na França, na UERJ não há o registro de historiadores envolvidos. O próprio formato das entrevistas é muito mais próximo de um programa de TV, com um repórter que cumpre o papel de apresentador e entrevistador. A duraçáo dos depoimentos, que variam entre 40 minutos e 1 hora e 20 minutos, também são bem diferentes das entrevistas de profundidade que compóem um programa de História Oral, tal como delineado por Alberti (2013). Ao longo da pesquisa, tivemos acesso a DVDs com as gravaçóes originais digitalizadas e somos responsáveis pelas transcriçôes citadas ao longo do artigo.

Apesar dessas ressalvas, acreditamos que os depoimentos produzidos no âmbito do Memória UERJ são muito ricos por revelarem a visão de mundo dos reitores que conduziram uma etapa fundamental da construção da universidade, o modo como eles próprios compreendiam os seus papéis nesse processo, as motivaçóes que os animavam nessa empreitada, os conflitos e as alianças internas e com o mundo político da cidade do Rio de Janeiro. Lisboa da Cunha e Lyra Filho se enquadram na categoria de "grandes testemunhas", como propôs Danièle Voldman (2015), pois trazem "a consciência de terem participado dos acontecimentos do seu tempo e de terem influenciado o seu curso" (Voldman, 2015, p. 41).

Assim, é sobre esses depoimentos que nos debruçamos agora enfocando três momentos da trajetória da universidade: os seus "tempos heroicos"; a chegada ao Maracanã e a remoção da Favela do Esqueleto; e a construção do campus e a expansão da universidade.

\section{A fundação da UERJ e os seus "tempos heroicos"}

Tive um período inicial de grandes dificuldades. Talvez pudéssemos chamar de tempos heroicos da universidade. Era uma universidade mal arrumada, mal saída do ato de fundação, sem recursos, sem organização administrativa, sem uma definição exata de sua estrutura judicial, enfim, atravessamos dificuldades muito sérias, e nesta primeira fase, há que ser assinalado o apoio do governo federal. Foi a fase que nós realmente começamos a receber apoio do governo federal através de vários auxílios que nos permitiram sair das dificuldades maiores em que nos encontrávamos. Bastará que se assinale que a universidade nessa fase não possuía nenhum veículo, salvo aqueles que mais tarde foram integrados ao Hospital Pedro Ernesto, que não era da universidade. $\mathrm{O}$ primeiro auxílio federal conseguido a duras penas nos 
permitiu comprar uma pequena caminhoneta, primeiro veículo que com nós procuramos cumprir a nossa função não só no transporte de autoridades, como também nas compras, na atuação de transporte de materiais, enfim, de todos os serviços da universidade. Uma única caminhoneta DKV. Foi nosso primeiro veículo. Isso define bem a fase inicial desta universidade. (Haroldo Lisboa da Cunha, 1980).

É com as palavras acima que o ex-reitor Haroldo Lisboa da Cunha inicia o seu depoimento para o programa Memória UERJ, em setembro de 1980. Lisboa da Cunha destaca a ausência de recursos materiais, humanos e financeiros e procura enfatizar a precariedade que ele, enquanto reitor, foi obrigado a enfrentar. Esse contraste entre a universidade que recebeu e a universidade que entregou é a tônica que atravessa todo o depoimento do ex-reitor. Chama atenção, inclusive, que Lisboa da Cunha não fale sobre sua própria trajetória nem como chegou ao posto. Deste modo, é importante apresentar sucintamente seu caminho pregresso: catedrático de Matemática do Colégio Pedro II e fundador da Faculdade de Filosofia, Ciências e Letras do Instituto La-Fayette, em 1939, onde também atuou como docente. Após deixar a reitoria, assumiu a direção do Instituto de Matemática e Estatística da universidade.

$\mathrm{Na}$ sua fala, o ex-reitor afirma que a universidade estava "mal saída do ato de fundação". Apesar de ter sido criada em 1950, a UERJ viveu sua primeira década de vida em crise permanente. Essa instabilidade vem desde a própria criação da instituição, por iniciativa de vereadores do então Distrito Federal. O projeto de lei que encampou as quatro faculdades particulares para criar a nova universidade foi apresentado em 1948 na Câmara Municipal dos Vereadores. Em outubro de 1950, sob forte pressão de alunos e professores das faculdades, que sofriam com problemas financeiros, a Câmara aprovou o projeto. $\mathrm{O}$ prefeito Ângelo Mendes de Moraes, entretanto, vetou a iniciativa com a alegação de falta de recursos e o fato de já existir uma universidade na cidade do Rio de Janeiro, mantida pelo governo federal, a Universidade do Brasil (Mancebo, 1996). Como, na época, os vetos do prefeito do Distrito Federal eram analisados pelo Senado Federal, o campo de batalha em torno da nova universidade se transferiu para o legislativo federal. A luta pela criação da UERJ foi um marco que sedimentou entre os professores fundadores certa visão heroica sobre a própria atuação no episódio. Lisboa da Cunha narra os acontecimentos que antecederam a derrubada do veto em seu depoimento:

Tivemos professores em vigília constante em todos os lugares. Nós diminuímos as nossas tarefas. E muitas vezes, no Senado mesmo, as sessóes foram várias, em várias ocasióes o veto esteve em votação, faltava número, 
de repente havia qualquer coisa, era retirado maliciosamente e nós nos revezávamos na permanência daquela vigília que perdurou muito tempo. Nós nos revezávamos, procurávamos os nossos senadores conhecidos, levávamos a eles as razóes, apontávamos as vantagens e os sensibilizávamos constantemente. Um grupo numeroso e que trabalhou eficientemente.

Quando nós sentíamos que perigava a queda do veto, nas antessalas cochichávamos, chamávamos os nossos senadores mais chegados ao pleito, e conseguiam geralmente a retirada do projeto. Foi retirado duas ou três vezes, se não me falha a memória. Até que no dia em que sentimos maioria absoluta para votação, por volta de uma ou duas horas da madrugada, ele foi votado, isto é, foi derrubado o veto.

É claro que por vezes, quando sentíamos que iria haver dificuldades na votaçáo, vamos confessar esses pequenos pecados, aqueles senadores que sabíamos declaradamente contrários, nós procurávamos atraí-los ao corredor, mandávamos chamar e naturalmente, atenciosos, como todo congressista é, muitas vezes nos atendiam. Nós queríamos ter a segurança da queda do veto e conseguimos com uma margem muito sensível, não foi uma pequena margem. E foi derrubado por uma margem razoável, uma margem afirmativa no Senado Federal. (Haroldo Lisboa da Cunha, 1980).

As estratégias adotadas pelos professores em defesa da queda do veto e da encampação pelo Distrito Federal são reveladoras de sua forte atuação política. O próprio fato de o projeto ter sido apresentado por um vereador, e não pelo Executivo municipal, já aponta para a articulação entre os docentes e o campo político da cidade. $\mathrm{Na}$ época, os vereadores atuavam primordialmente e intensamente no encaminhamento de demandas específicas de suas bases (Freire; Sarmento, 2004), o que explica o apelo do projeto. O corpo a corpo nos corredores com os parlamentares, as vigílias e as manobras para evitar a derrota foram marcantes para o grupo que, uma década mais tarde, assumiria o comando da instituiçáo. $\mathrm{O}$ fato de vários docentes exercerem atividades fora da universidade, seja no Colégio Pedro II, cujos catedráticos como Lisboa da Cunha gozavam de grande prestígio, seja no Judiciário, como era o caso de diversos professores da Faculdade de Direito, também colaborou para a derrubada do veto. Eram homens experimentados em funçóes públicas, que conheciam os meandros do poder e que utilizaram suas posiçóes para fazer valer seus interesses. $\mathrm{O}$ ex-reitor também destaca a participação dos estudantes:

Os alunos nos acompanharam sempre. Porque afinal de contas as faculdades 
naquela ocasião eram todas elas pagas e, vamos dizer, as anuidades não eram pequenas, como sói acontecer hoje em todas as faculdades de natureza privada. Agora, a organização da universidade pressupunha o pagamento da universidade pelo Estado, pelo Distrito Federal. O Distrito Federal, no projeto, faria apenas a eleição do reitor, de alguns funcionários e além disso pagaria as anuidades dos alunos. Ora, aí estava um interesse material que os sensibilizariam se não houvesse outros motivos para sensibilizá-los. Bastaria isso, mas nós também os tivemos sempre juntos de nós em todos os momentos em que procuramos os órgãos públicos. Fosse a Câmara dos Vereadores, fosse o Senado Federal, fosse o próprio governo, o Executivo da cidade a quem recorremos ao final para que não saísse afinal o que saiu, o veto do projeto. (Haroldo Lisboa da Cunha, 1980).

Como aponta Lisboa da Cunha, a gratuidade do ensino era uma bandeira que mobilizava os estudantes e a participação do corpo discente foi fundamental para o sucesso da empreitada, que decorreu também de um contexto político favorável ao pleito. De acordo com Cunha (2007), os senadores estavam muito permeáveis às pressóes de estudantes e professores das faculdades privadas, desejosos dos privilégios do funcionalismo público. A prática de encampar instituiçóes privadas para criar universidades públicas era recorrente. No dia 4 de dezembro de 1950, na mesma sessão que o veto de Mendes de Moraes foi derrubado e a UERJ foi criada, foi aprovada a Lei $n^{\circ} 1.254,{ }^{4}$ que "federalizou" 39 estabelecimentos de ensino. Com o financiamento da Uniáo, estava aberto o caminho para que fossem reunidos em universidades nos anos seguintes (Cunha, 2007). A trajetória da UERJ não fugiu ao padrão do período.

Se a derrubada do veto foi um passo fundamental para a criação da universidade, a sua efetivação seria muito mais complicada. A decisão do Senado determinava que o prefeito nomeasse, em 30 dias, uma comissão de professores das quatro faculdades para tomar as providências necessárias à sua instalação. No entanto, Mendes de Moraes resistiu o quanto pôde. Os nomes da comissão só foram indicados em julho de 1951, já na gestão de João Carlos Vital. Eram eles: Lourenço Filho, da FFCL, Ary Franco, da Faculdade de Direito, Álvaro Cumplido de Sant’Anna, da Faculdade de Ciências Médicas, e Cândido de Almeida Marques, da Faculdade de Ciências Econômicas. Apenas em 15 de fevereiro de 1952, em solenidade no Palácio Guanabara, o professor Rolando Monteiro, da Faculdade de Ciências Médicas, foi empossado como primeiro reitor (Pardal, 1990), 14 meses após a votação no Senado.

4 Disponível em: <http://www.planalto.gov.br/ccivil_03/LEIS/1950-1969/L1254.htm>. Acesso em: 2 jun 2020. 
Contudo, a formalização da sua existência não era suficiente para sanar problemas muito mais profundos. As quatro faculdades tinham trajetórias, culturas acadêmicas e ordenamentos jurídicos distintos. De acordo com Mancebo (1996), o ponto de uniáo era apenas uma concepçáo comum quanto ao objetivo de uma instituição de ensino superior: a preocupação exclusiva com a formação profissional. $\mathrm{O}$ modo como o patrimônio de cada uma das faculdades seria incorporado à nova universidade também não estava claro e se arrastou por anos. A instabilidade jurídica e administrativa permaneceu nos primeiros anos e só começou a ser resolvida com a concentração de poderes na reitoria, em 1959, pouco antes de Lisboa da Cunha assumir o posto. Assim o ex-reitor definiu o cenário que encontrou:

Era um verdadeiro conglomerado, um arquipélago de escolas, era um conglomerado mal definido em sua estruturação. Todas as vezes que por qualquer dificuldade no trato de nossos compromissos perante os funcionários tivemos que comparecer à Justiça do Trabalho, não sabíamos responder a primeira pergunta do juiz: qual é a estrutura da universidade? A bem dizer, a cabeça, vale dizer, o reitor e alguns funcionários, eram funcionários do estado, os alunos tinham as suas anuidades pagas pelo então Governo do Distrito Federal, nada mais do que isso. As faculdades continuavam com as suas administraçóes inteiramente independentes. Portanto, poder-se-á julgar hoje como era difícil administrar a universidade. Reitor, funcionário do estado, seis ou oito funcionários, era tudo que possuía a então reitoria. E cada faculdade com sua vida independente, seus funcionários, seus quadros, suas organizaçóes, seus horários, seus regimes. Eis um panorama do que hoje poderíamos chamar de os tempos heroicos da universidade. (Haroldo Lisboa da Cunha, 1980).

A partir desse diagnóstico, o passo seguinte era superar a fragmentação e construir uma universidade "de verdade". Antes, porém, de construir as instalaçôes físicas era necessário desenhar que universidade seria essa e onde ela ficaria localizada. Os debates, os estudos e as definiçóes sobre esses temas marcaram os anos de gestáo de Lisboa da Cunha e serão abordados a seguir.

\section{Os planos de reestruturação e a chegada ao Maracanã}

O início do mandato de Lisboa da Cunha na reitoria da UERJ coincide com uma série de acontecimentos que constituíram um ponto de virada para a 
instituição. A Constituição do Estado da Guanabara 5 , promulgada em março de 1961, garantiu à universidade o status jurídico de fundação com "autonomia didática, financeira, administrativa e disciplinar” - o que a permitia contratar professores como celetistas -, e uma subvenção "nunca inferior a 2,5\% da arrecadação tributária estadual". A garantia de uma fonte segura de financiamento era uma mudança radical para uma universidade que sofria desde a fundação com a falta de recursos. Ao mesmo tempo, a UERJ entrou nos planos políticos do governador Carlos Lacerda, da Uniāo Democrática Nacional (UDN), que assumiu o posto em dezembro de 1960 e tinha a Educação como uma de suas prioridades (Perez, 2005). Uma das primeiras medidas dessa sinergia foi a implantação da Faculdade de Engenharia, que nasceu com o objetivo de formar quadros técnicos para o Estado. A faculdade já tinha sido criada formalmente em 1955, por decisão do Conselho Universitário, mas faltavam verbas para que saísse do papel. Segundo Mancebo (1996), a relação entre o governador da Guanabara e os líderes universitários era de cooperação e lealdade, com Lacerda assumindo de verdade o posto de chanceler e acompanhando de perto o desenvolvimento da instituição.

Essa proximidade, entretanto, se tornou motivo de conflitos entre a UERJ e o governador quando se iniciaram as discussôes sobre a sua reestruturação. Em fevereiro de 1962, o consultor greco-americano Rudolph Atcon visitou a universidade. Especializado na reestruturação de instituiçóes de ensino superior na América Latina, Atcon já tinha atuado no Brasil como assessor de Anísio Teixeira na Campanha de Aperfeiçoamento de Pessoal de Nível Superior (CAPES), na década de 1950 (Fávero, 1991). Em 1962, o objetivo de sua visita era vender seus serviços para auxiliar a UERJ a planejar sua reestruturaçáo e contava com um aliado de peso: o próprio Carlos Lacerda (Cunha, 1988). No entanto, a possível contrataçáo do consultor estrangeiro foi mal vista pelos dirigentes universitários. Em seu depoimento, Lisboa da Cunha é perguntado se "é verdade que o reitor Haroldo Lisboa da Cunha em determinado momento enfrentou o grande político da época, o governador Carlos Lacerda?". Na resposta, o ex-reitor prefere um tom bem menos épico do que o do entrevistador:

Tivemos um pequeno incidente em 1962. Sua Excelência, naturalmente entusiasmada com o sucesso da universidade, com o crescimento da universidade, com o prestígio que já vinha assumindo dentro e fora dos limites do estado, Sua Excelência pensou em trazer um elemento de grande

5 O estado da Guanabara, criado em 1960 após a transferência da capital federal para Brasília, existiu até março de 1975, quando houve a fusão com o estado do Rio de Janeiro. Disponível em: <http:// bibliotecadigital.fgv.br/ojs/index.php/rdpcp/article/viewFile/59316/57749>. Acesso em 2 jun. 2020. 
renome internacional para nos orientar em nossos destinos. Nós não achamos razoável que isso assim se processasse. Sua Excelência julgava também que deveríamos ter fora do país um centro de radiação luminosa, como é Paris, um representante. Nós dividíamos as dificuldades. Concedemos uma parte e negamos outra. A universidade como talvez nunca tenha estado. E que não houve uma voz discordante. Junta e apoiando o reitor, mostrando convincentemente ao governador Carlos Lacerda que ela de fato não desejava a entrega dos destinos da universidade a um elemento que viria de fora, embora homem conceituado, etc., com trabalhos universitários em diversos países da América Latina. Em compensação aceitou a ideia de um representante em Paris, mantivemos um representante em Paris por vários anos. (Haroldo Lisboa da Cunha, 1980).

De fato, em $1^{\circ}$ de outubro daquele ano, o Conselho Universitário seguiu o parecer do conselheiro João Lyra Filho pela "inoportunidade da contratação de técnico estrangeiro em organizaçáo universitária” (UEG, 1962a, p. 10) com apenas um voto contrário, do então vice-reitor e professor da Faculdade de Ciências Médicas, Álvaro Cumplido de Sant'Anna. A negativa, entretanto, não deve ser lida como uma rejeição à reforma da universidade, mas, antes, uma tomada de posição dos dirigentes da instituição em defesa de sua autonomia. Tanto a reestruturação era uma prioridade que, em 30 de julho de 1962 - entre a visita de Atcon e a rejeição de sua contratação -, o Conselho Universitário aprovou a criação de uma comissão para elaborar o plano decenal de desenvolvimento e expansão da universidade. No dia 6 de agosto, o Conselho Universitário homologou os nomes indicados por Lisboa da Cunha para a comissão: Tarcísio Meirelles Padilha, pela FFCL, como presidente; Sydney Martins Gomes dos Santos, pela Faculdade de Engenharia; Mozart Ferreira D'Azevedo, pelos Órgãos de Colaboração; George Sumner Filho, pela Faculdade de Ciências Médicas; Maria da Conceição Miragaia Pitanga, pela Faculdade de Ciências Econômicas; e Célio de Oliveira Borja, pela Faculdade de Direito (UEG, 1962b, p. 10).

O documento produzido pelo grupo foi encaminhado ao Conselho Universitário em 13 de fevereiro de 1963, mas infelizmente se perdeu com o tempo. Contudo, a sua principal contribuiçẫo foi a sugestáo do local onde deveria ser instalado o campus universitário, como lembrou o ex-reitor em seu depoimento:

Devemos o campus inicialmente a um parecer de uma comissão que estudou cansativamente todas as possíveis localizaçóes de uma universidade nessa área do Distrito Federal, e depois Guanabara, e hoje cidade do Rio de Janeiro. Essa comissão era presidida pelo eminente professor Tarcísio 
Meirelles Padilha, nosso companheiro ainda hoje. Ao termo do seu relatório, dizia Padilha: "o melhor lugar indiscutivelmente é o local onde se situa a chamada Favela do Esqueleto. Infelizmente, a remoção dessa favela não é coisa possível, pelo menos diante da situação atual." Isto teria sido dito por Padilha por volta de julho de 1965 . No dia 29 de setembro do mesmo ano, o governador Carlos Lacerda, anunciava a remoção total da então Favela do Esqueleto para a Vila Kennedy e fazia simbolicamente a entrega daquele esqueleto que há mais de 20 ou 30 anos estava abandonado à universidade. Embora se tratasse de um terreno federal, portanto deveria haver uma lei transferindo o uso do terreno. (Haroldo Lisboa da Cunha, 1980).

A construção de campi universitários era um imperativo da reforma universitária que vinha sendo gestado no país desde a década de 1950 (Cunha, 2007) e da necessidade de garantir acesso ao ensino superior a um contingente crescente de jovens. Eram os chamados "excedentes" que, apesar de aprovados na seleçáo para as universidades, não encontravam vagas disponíveis. Havia um consenso, compartilhado pela direita e pela esquerda, que o ensino superior brasileiro precisava mudar para atender às demandas sociais e econômicas que se impunham - apesar dos grupos políticos apresentarem respostas distintas para essas demandas (Motta, 2014). Os campi eram fundamentais para modernização das instituições, ainda caracterizadas pela Reforma de Francisco Campos, de 1931. Essa modernização implicava numa reorganização dos recursos materiais e humanos:

Ao invés de agrupá-los em função dos produtos profissionais (isto é, nas faculdades), passavam a ser agregados em funçâo das economias de escala no uso dos indutos (implicando na estrutura departamental). O conhecimento a ser ensinado se fragmentava em pequenas unidades chamadas disciplinas, já descoladas das matérias correspondentes às cátedras. No nível da universidade, a agregação das disciplinas dava origem aos departamentos, por processos indutivos (ao contrário do processo dedutivo que originava a cátedra); no nível do estudante, resultava no currículo, mediante um sistema peculiar de contabilidade - o crédito. (Cunha, 1988, p. 18, grifos no original).

Esse desenho organizacional descrito por Cunha só poderia ser realizado se todas as unidades acadêmicas compartilhassem o mesmo espaço físico. A linha de força desse movimento era a racionalização administrativa, pedagógica e econômica ou, nos termos legais da Reforma Universitária de 1968, a proibição da duplicação de meios para fins idênticos. Junto com os campi, vinham a introdução da organização por departamentos e do sistema de créditos, assim como a criação 
dos institutos básicos e das escolas profissionais. O caráter emancipatório e inclusivo da reforma, presente nos projetos das esquerdas pré-1964, foi excluído pela ditadura civil-militar e prevaleceu a "modernização autoritário-conservadora" (Motta, 2014a).

O caminho seguido pela UERJ foi dessa "modernização autoritárioconservadora". Após a comissão presidida pelo professor Tarcísio Meirelles Padilha concluir seus trabalhos, em fevereiro de 1963, outro grupo foi montado, desta vez com membros externos à universidade - em seu depoimento, Lisboa da Cunha funde os trabalhos das duas comissóes de planejamento. A presidência da segunda comissão ficou com o então vice-governador Rafael de Almeida Magalhães. Outro colaborador externo foi Frank Tiller, diretor de Assuntos Internacionais da Universidade de Houston. Este grupo apresentou seus trabalhos não ao Conselho Universitário, mas ao próprio Lisboa da Cunha. Com o anúncio da remoção da Favela do Esqueleto por Lacerda, em setembro de 1965, o então reitor realizou uma síntese das contribuições das duas comissōes no Plano de Reestruturação da UEG, apresentado em novembro do mesmo ano (UEG, 1965).

A Favela do Esqueleto recebeu esse nome por ter se desenvolvido na estrutura inacabada de um hospital, cuja construção foi iniciada em 1928 e paralisada em 1930. A escolha do terreno marcou a confluência de interesses tanto da universidade quanto do governador Carlos Lacerda. De parte da UERJ, o terreno estava localizado entre a Faculdade de Ciências Médicas e o Hospital Pedro Ernesto, em Vila Isabel, e a Faculdade de Engenharia, em São Cristóvão, consideradas as instalações em melhores condiçóes. Já Lacerda, fazia da remoção de favelas uma bandeira sua desde fins dos anos 1940, quando liderou uma campanha na imprensa intitulada "A Batalha do Rio" para que as comunidades fossem tratadas como um "complexo conjunto de problemas nacionais" (Leeds; Leeds, 1978, p. 202). Em seu mandato de governador do estado da Guanabara, entre 1961 e 1965, foram removidas total ou parcialmente 30 favelas (D'Assumpção, 2007).

A remoção da Favela do Esqueleto não ocorreu sem resistência. Desde o ano anterior, os moradores se organizaram para evitar a transferência para a Vila Kennedy, conjunto habitacional construído com fundos norte-americanos na Zona Oeste do Rio de Janeiro (Leeds; Leeds, 1978). Eles tentaram até realizar um plebiscito sobre a remoção, mas foram proibidos pela polícia. O presidente da Federaçáo das Associaçóes de Favelas do Estado da Guanabara (FAFEG), Etevaldo Justino de Oliveira, ficou cinco dias preso no Departamento de Ordem Política e Social (DOPS) sem acusaçáo formal, entre 10 e 15 de dezembro de 1964, por "esquentar o ambiente na Favela do Esqueleto" (Polícia liberta... 1964).

A universidade não ficou alheia ao processo de remoção. Em meio à resistência dos moradores a deixar a favela, a instituição ofereceu o auxílio dos seus alunos ao governo do estado, como narrou Lisboa da Cunha em seu depoimento: 
Problemas houve muitos. Inclusive quando a universidade, para coadjuvar os trabalhos dos assistentes sociais do estado, que promoviam a remoção dos favelados para a Vila Kennedy, quis que seus alunos da Faculdade de Serviço Social a eles se associassem, esses estudantes foram vigorosamente repelidos. Maltratados, chegando alguns mesmo a serem surrados. Tivemos que retirá-los às pressas do serviço porque, se identificados, corriam o risco até de serem mortos. (Haroldo Lisboa da Cunha, 1980).

O ex-reitor não demonstra nenhum tipo de arrependimento ou reavaliação sobre a colaboração dada pela universidade durante a remoção. Pelo contrário, ele deixa claro seu espanto com o tratamento dispensado aos alunos de Serviço Social que foram auxiliar no trabalho de transferência. Essa visão é significativa do alinhamento existente entre os dirigentes universitários e o governo de Lacerda, mesmo em suas medidas mais violentas. Mais adiante, no depoimento, Lisboa da Cunha reforça que compartilhava da mesma posição do governador ao citar o seu discurso quando o terreno do campus foi entregue à universidade:

Quando nós tomamos conta simbolicamente do campus, isso num dos dias de outubro de 1965, foi armado um palanque onde o governador Carlos Lacerda se dirigiu aos favelados que ainda se encontravam perambulando e retirando alguns pertences por aqui, dizendo-lhes que onde eles conheceram a miséria, iria ser erguida uma universidade e que ele fazia votos para que os filhos desses favelados pudessem um dia vir da Vila Kennedy e transpor os pórticos da universidade, que os receberiam de braços abertos para que tivessem um futuro melhor que o de seus pais. (Haroldo Lisboa da Cunha, 1980).

Os "favelados" ainda levariam mais de quatro décadas para "transpor os pórticos da universidade" e começar a superar o violento ato de exclusáo em que foi fundado o campus do Maracanã. Do lado da reitoria, sua preocupação era dar o pontapé inicial nas obras das futuras instalaçóes universitárias. Antes de avançar para os obstáculos enfrentados após a definição do terreno, é preciso fazer algumas ressalvas em relação à aliança entre os dirigentes universitários e Lacerda. Mais do que uma identidade política comum, udenista e liberal - vários professores estavam alinhados ao nacionalismo desenvolvimentista, por exemplo - o que os uniu foi uma defesa pragmática dos seus respectivos interesses. Uma universidade estadual forte na Guanabara interessava ao projeto político do governador e uma UERJ forte interessava aos seus dirigentes. Essa postura pragmática explica a proximidade mantida pelos reitores com os governadores seguintes, de oposição a Lacerda, Negrão de Lima (1965-1970) e Chagas Freitas (1970-1975). 


\section{A construção do campus}

Apesar da remoção da antiga Favela do Esqueleto ter sido levada a cabo pelo governo da Guanabara, o terreno pertencia ao governo federal. Para que a universidade tomasse posse de fato da área era preciso uma decisão do então Presidente da República, marechal Humberto de Alencar Castelo Branco. De acordo com o depoimento de Lisboa da Cunha, o vice-governador Raphael de Almeida Magalhães fez o pedido da cessão do terreno em 5 de dezembro de 1965 . Contudo, a Lei Federal $\mathrm{n}^{\circ} 5.178$ que repassou a área à UERJ foi sancionada apenas no dia $1^{\circ}$ de dezembro de $1966 .{ }^{6}$ Como a posse definitiva só no fim do mandato de Lisboa da Cunha, o início das obras do campus foi efetivado pelo seu sucessor, João Lyra Filho. Em seu depoimento ao Memória UERJ, Lyra Filho exalta a sua responsabilidade pela construção do campus do Maracanã. $\mathrm{O}$ exreitor confere a si um protagonismo exagerado e se apresenta como um líder capaz de realizar aquilo que todos duvidavam ser possível de fazer - o que, como vimos, não era verdade. Diz Lyra Filho:

Veio entáo à baila o meu desejo de construir o campus da universidade. Sem recursos, sem local adequado, sem projeto. Enfrentamos o problema e eu tive por mim a assessoria fecunda, ativa, assídua de um professor da universidade, hoje meu dileto amigo, o professor Wilson Choeri. Com sua ajuda, metemos a máo a obra. Diante de todo mundo o pessimismo. Ninguém acreditava: professores, alunos, funcionários. Ninguém acreditava que nós construíssemos aquele campus. Havia ali os restos da favela do esqueleto, que de imediato transformamos no atual pavilhão reitor Haroldo Lisboa da Cunha. Não demorou a empresa um ano. Feita a construção, diante dos olhos estupefatos de todo mundo, passamos a construçáo do verdadeiro campus universitário. (João Lyra Filho, 1980).

"Sem recursos, sem local adequado, sem projeto". A declaração de Lyra Filho faz parecer que pouco havia sido feito antes de sua posse na reitoria. $\mathrm{Na}$ verdade, apesar disso ser omitido em seu discurso, sua gestấo deu continuidade ao plano desenhado por Lisboa da Cunha. O problema da localização do campus da universidade já havia sido equacionado em dezembro de 1966. A decisão de se aproveitar a estrutura da antiga Favela do Esqueleto também havia sido tomada. O ponto em que o ex-reitor é preciso, é na ausência de recursos. A Constituição

6 Disponível em: <https://legis.senado.leg.br/norma/547040/publicacao/15641964>. Acesso em: 2 jun. 2020. 
do Estado da Guanabara havia garantido um percentual da arrecadação tributária estadual para a universidade. Contudo, a construção do novo campus exigia uma soma significativa de recursos não só para erguer os prédios, mas também para desapropriar áreas vizinhas ao terreno cedido pelo governo federal. Afirma Lyra Filho:

Tive eu que pôr a mão na obra, com certeza de imediatismo, e assim se deu início a construção. Sob os olhos surpreendidos de todos os espectadores. Tivemos que desapropriar várias outras áreas de imóveis que circundavam o terreno no campus. A área doada não era o bastante. Tivemos que obter recursos para aquisição dos imóveis nessas áreas e o campo foi alargado, aumentado, é hoje a obra que todos vocês conhecem. (João Lyra Filho, 1980).

A soluçáo encontrada por Lyra Filho para arcar com todas essas despesas foi promover um verdadeiro "arrocho" nas contas da instituição a fim de, com verbas próprias, garantir a execução das obras. Esse papel de gestor é destacado em seu depoimento. Como exemplo da capacidade financeira alcançada pela universidade, o ex-reitor narra um episódio em que o próprio governador da Guanabara, Negrão de Lima, pediu um empréstimo à instituição:

De uma feita, financeiramente, não obstante a construção do campus, o dinheiro que nós consumíamos ali, retendo nomeaçóes, retendo despesas supérfluas, cresceu tanto que pudemos adquirir obrigaçóes do tesouro, incluir recursos em poupança, fazer operaçôes de funcionamento que se elevavam a 30, 40, 50 milhóes de cruzeiros naquele tempo. Um dia, o próprio governador do estado, no fim do ano de 1969, em situaçáo de apertura financeira, chamou-me. Para pedir o que? Um empréstimo. O tesouro público do estado pedia à universidade do estado, sua subordinada, 17 milhôes de cruzeiros emprestados para aquisição de medicamentos destinados aos hospitais do estado. E assim se fez. E assim aconteceu para júbilo da universidade. (João Lyra Filho, 1980).

É necessário ressaltar que a construção do campus era condição sine qua non para a materialização da reorganização da universidade. Oficialmente, esse processo já tinha começado com a Resolução n² 296,7 de 14 de outubro de 1966, assinada por Lisboa da Cunha. A medida criou os Institutos Básicos de Física,

7 Disponível em: <http://www.boluerj.uerj.br/pdf/re_02961966_14101966.pdf >. Acesso em: 2 jun. 2020. 
Química, Matemática e Estatística, Desenho e Artes Aplicadas, e Geociências, tal como prescrito no Plano de Reestruturação da UEG. Contudo, com exceção do Instituto de Física, que já tinha se separado da Faculdade de Filosofia, Ciências e Letras, os outros só entrariam em funcionamento com o novo campus. Para alcançar esse objetivo, ele promoveu uma reforma administrativa para centralizar os poderes na reitoria. A sua principal inovação foi a criação da Secretaria Geral da universidade com a atribuição de coordenar toda a administração (UEG, Resolução n 318,1967$).{ }^{8}$ Wilson Choeri foi o catedrático escolhido para o posto.

Logo no primeiro mês de gestâo, Lyra Filho também adotou uma série de medidas para segurar os gastos. Entre as medidas destacam-se: nenhuma admissão poderia ser feita antes da aprovação pelo Conselho Universitário do quadro de servidores da universidade, que ainda seria elaborado (UEG, Ato Executivo $\mathrm{n}^{\circ} 1$ 1, 1967); ${ }^{9}$ nenhuma admissão poderia ser realizada sem ato de aprovação do reitor (UEG, Ato Executivo $n^{\circ} 2$, 1967); ${ }^{10}$ nenhuma despesa sem prévia autorização do reitor seria paga e os processos de gastos iniciados antes da medida deveriam ser arquivados (UEG, Ato Executivo n $\left.{ }^{\circ} 6,1967\right) ;{ }^{11}$ todas as compras de material ficariam a cargo da Comissão de Compras de Materiais, salvo em casos de comprovada urgência (UEG, Ato Executivo n ${ }^{\circ}$ 6, 1967). O reitor também estabeleceu novas formas de controle do trabalho docente, com apuração da frequência de todos os servidores (UEG, Ato Executivo n $\left.{ }^{\circ} 10,1967\right) .{ }^{12}$

A centralização burocrático-administrativa e a organização dos institutos básicos na UERJ, entre 1966 e 1967, ia ao encontro da modernização autoritáriaconservadora em andamento em nível federal. Os primeiros atos legais da Reforma Universitária foram os Decretos-Lei $\mathrm{n}^{\circ} 53^{13}$ e $\mathrm{n}^{\circ} 252,{ }^{14}$ de novembro de 1966 e fevereiro de 1967, respectivamente, baixados na gestâo de Raymundo Moniz de Aragão no Ministério da Educação (MEC). Os atos determinaram a unidade entre ensino e pesquisa, e sua concentração em institutos básicos, além de introduzirem a organizaçáo por departamentos. Para Aragão, que depois assumiu a reitoria da UFRJ, a reforma era "um processo que se inicia e prossegue numa série de medidas efetivadoras", ou seja, não seria realizada apenas com a edição de normas legais pelo governo federal (Bomeny, 1994, p. 7).

Disponível em: <http://www.boluerj.uerj.br/pdf/re_03181967_16061967.pdf>. Acesso em: 2 jun. 2020.

Disponível em: <http://www.boluerj.uerj.br/pdf/ae_00011967_06061967.pdf>. Acesso em: 30 jun. 2020.

Disponível em: <http://www.boluerj.uerj.br/pdf/ae_00021967_06061967.pdf>. Acesso em: 2 jun. 2020.

Disponível em: <http://www.boluerj.uerj.br/pdf/ae_00061967_12061967.pdf>. Acesso em: 30 jun. 2020.

Disponível em: <http://www.boluerj.uerj.br/pdf/ae_00101967_26061967.pdf>. Acesso em: 30 jun. 2020.

Disponível em: <http://www.planalto.gov.br/ccivil_03/decreto-lei/1965-1988/Del0053.htm>. Acesso em: 30 jun. 2020.

Disponível em: <http://www.planalto.gov.br/ccivil_03/Decreto-Lei/1965-1988/Del0252.htm>. Acesso em: 30 jun. 2020. 
Esse alinhamento entre as esferas estadual e federal reflete a circulação das concepçóes de reforma universitária antes mesmo da Lei $\mathrm{n}^{\circ} 5.540,{ }^{15}$ de novembro de 1968. Apesar de ter sido efetivada durante a ditadura civil-militar, a participação de docentes na sua formulação e implantação foi muito intensa. É de se destacar o papel exercido pelo Conselho Federal de Educaçáo (CFE) nesse processo, responsável pelo texto dos dois decretos baixados na gestão Aragáo (Rothen, 2008). Contudo, o exemplo mais bem acabado do protagonismo civil na área educacional foi o Grupo de Trabalho da Reforma Universitária (GTRU), montado em agosto de 1968 e que elaborou o texto da Lei n ${ }^{\circ} 5.540$. Composto só por civis, incluía membros do CFE, como Valnir Chagas e Newton Sucupira, e lideranças universitárias como o próprio reitor da UERJ, João Lyra Filho, e o reitor da Pontifícia Universidade Católica do Rio de Janeiro (PUC-Rio), Fernando Bastos de Ávila. Para retomar as categorias trabalhadas por Motta (2014), se é fato que houve forte repressão das universidades durante a ditadura civil-militar, também houve conciliação e acomodação. A mobilização de laços e fidelidades pessoais, características da nossa cultura política, estiveram presentes na modernizaçáo autoritária-conservadora do ensino superior.

É o que se observa na própria gestão de Lyra Filho. Para além do arrocho interno, ele utilizou suas conexóes pessoais para revitalizar e ampliar o patrimônio da universidade. Com uma longa carreira em funções públicas, cujo início remonta ao Estado Novo (Silva, 2004), e sendo irmão do general Aurélio de Lyra Tavares, ministro do Exército no governo de Artur da Costa e Silva, a proximidade política e familiar com o poder se misturavam na sua atuação, como no caso da incorporação do prédio onde por anos funcionou o colégio de aplicação da UERJ.

Outra aquisição desse tempo foi o prédio onde hoje funciona o colégio de aplicação na Rua Barão de Itapagipe. O edifício, que é uma chácara, pertencia ao próprio estado da Guanabara. Diligenciei junto aos poderes públicos, o governo, o Executivo, a Assembleia Legislativa, e conseguimos para a universidade a aquisição do imóvel que hoje está incorporado ao seu patrimônio. (João Lyra Filho, 1980).

O ex-reitor destaca também a articulação para transferir a sede da reitoria da Travessa Euricles de Matos, em Laranjeiras, para o Solar da Marquesa de Santos, em São Cristóvão:

Em determinado instante, nós depreendemos que náo valeria a pena mais manter a reitoria na Travessa Euricles de Matos, onde estava instalada. O

15 Disponível em: <http://www.planalto.gov.br/ccivil_03/leis/L5540.htm>. Acesso em: 30 jun. 2020. 
prédio era por demais acanhado. A universidade já estava na forma adulta, estava crescendo demais. Resolvemos então negociar com o governo do estado a transferência para a universidade, o edifício hoje chamado Solar da Marquesa de Santos, Avenida D. Pedro II, que tinha sido casa onde morava a concubina D. Pedro I. O prédio construído por um grande arquiteto francês estava totalmente depenado. As pinturas que ornamentavam as paredes dos salóes nobres haviam sido trocadas por outras de tinta comum. Restauramos totalmente aquele solar que passou a ser a sede da reitoria. (João Lyra Filho, 1980).

Observa-se, então, que o crescimento da universidade ocorreu não apenas com a construçáo do campus do Maracanã, mas em uma série de frentes diferentes. $\mathrm{Na}$ área biomédica, por exemplo, foi erguido o edifício Paulo de Carvalho, ao lado do hoje nomeado Hospital Universitário Pedro Ernesto (HUPE), no Boulevard 28 de Setembro, onde foram instaladas a Faculdade de Enfermagem, a Faculdade de Odontologia e a Faculdade de Serviço Social. Por isso, apesar do esforço de controle para garantir os recursos necessários às obras, a falta de verbas foi um problema recorrente em todos esses anos. Em São Cristóvão, houve investimentos também no prédio da Faculdade de Engenharia, localizado na Rua Fonseca Teles, hoje desativado, mas que ainda pertence à instituição.

Não à toa, a conclusáo dos prédios no Maracanã demorou muito mais do que o previsto. O pavilhão Haroldo Lisboa da Cunha, construído a partir da estrutura da antiga Favela do Esqueleto, foi inaugurado em agosto de 1970, com um atraso de um ano e cinco meses. Já o pavilhão batizado de João Lyra Filho, foi inaugurado março de 1976, no mandato do então reitor Oscar Accioly Tenório. Com seus nomes nas duas principais instalaçóes do campus do Maracanã, não resta dúvida que a atuação de Lisboa da Cunha e Lyra Filho foi decisiva para que o próprio campus existisse. Contudo, isso não faz desaparecer as contradiçóes de seus depoimentos e de seus gestos, espaços privilegiados para compreender como dois dirigentes que ajudaram a construir a universidade pretenderam consolidar o seu lugar na memória da instituição.

\section{Conclusão}

Este artigo foi elaborado para fazer parte de um dossiê que procura articular a História Oral com a trajetória das universidades e de seus profissionais. A opçáo por trabalhar com os depoimentos de dois reitores da UERJ, que comandaram a instituição ao longo de 12 anos, num período que marca a sua configuração 
tal como conhecemos hoje, buscou acessar, pelas suas vozes, aquilo que não está registrado nas documentaçóes oficiais sobre a trajetória da universidade. Os depoimentos de Haroldo Lisboa da Cunha e de João Lyra Filho permitem conhecer os pequenos conflitos, as disputas de poder que envolveram um processo complexo de construção de uma universidade estadual no coração da segunda maior cidade do país e que foi peça de projetos políticos de diferentes governadores. As palavras dos reitores também são uma forma de matizar essa aliança entre dirigentes universitários e lideranças políticas, com suas contradiçóes e disputas. Também procuramos inserir a atuação dos dirigentes universitários no contexto mais amplo da reforma do ensino superior brasileiro levada a cabo nas décadas de 1960 e 1970, apontando o alinhamento entre o projeto da UERJ e as orientaçóes do governo federal. Em ambos os níveis, materializou-se uma "modernização autoritário-conservadora" (Motta, 2014a).

Os depoimentos são esclarecedores das visôes que esses dois homens tinham das suas açóes. Ambos se colocaram num papel heroico, de desbravadores de um "novo mundo" para a universidade. Se as contribuiçóes de Lisboa da Cunha e Lyra Filho foram decisivas para que a UERJ se tornasse a instituição que conhecemos hoje, é fato que suas açóes foram eivadas de ambivalências: fundar uma universidade a partir da remoção de uma favela, da qual foram partícipes, e, ao mesmo tempo, criar uma universidade de massas que fosse acessível a um número significativo de alunos. Os dois ex-reitores também deixaram suas memórias gravadas em um momento de mudanças políticas profundas no país, que chegariam à universidade alguns anos depois. Ao longo da década de 1980, uma nova geraçáo de professores chegou à reitoria e deu início a outro processo de transformação, que culminou com o pioneirismo na adoção na política de cotas (Ramadon, 2017). Algo que passava muito longe dos seus construtores nas décadas de 1960 e 1970.

\section{Referências}

ALBERTI, Verena. Manual de história oral. Rio de Janeiro: Editora FGV, 2013.

BOMENY, Helena. A reforma universitária de 1968: 25 anos depois. Revista Brasileira de Ciências Sociais. São Paulo, v. 9, n. 26, p. 51-65, out. 1994.

CUNHA, Luiz Antônio. A universidade reformanda: o golpe de 1964 e a modernização do ensino superior. Rio de Janeiro: Francisco Alves, 1988. 
Unesp, 2007.

D’ASSUMPÇÃO, Mônica de Matos Teixeira. Carlos Lacerda: demolidor de presidentes e construtor de um novo estado. Dissertação (Mestrado em Ciência Política) - UFF, Niterói, RJ, 2007.

FÁVERO, Maria de Lourdes de Albuquerque. Da universidade "modernizada" à universidade disciplinada: ATCON e Meira Mattos. São Paulo: Cortez, 1991.

FREIRE, Américo; SARMENTO, Carlos Eduardo. Três faces da cidade: um estudo sobre a institucionalização e a dinâmica do campo político carioca (1889-1969). In: MOTTA, Marly; FREIRE, Américo; SARMENTO, Carlos Eduardo. A política carioca em quatro tempos. Rio de Janeiro: Editora FGV, 2004.

LEEDS, Anthony; LEEDS, Elizabeth. A sociologia do Brasil urbano. Rio de Janeiro: Zahar, 1978.

LERNER, Samara Lima Tavares Mancebo. A Pós-graduação em Estudos de Problemas Brasileiros na UERJ: uma reflexão sociológica sobre um projeto de socializaçáa política no Brasil. Tese (Doutorado em Ciências Sociais) - UERJ, Rio de Janeiro, RJ, 2013.

LIMA, Gabriel Amato Bruno de. "Aula prática de Brasil": ditadura, estudantes universitários e imaginário nacionalista no Projeto Rondon (1967-1985). Dissertação (Mestrado em História) - UFMG, Belo Horizonte, MG, 2015.

MANCEBO, Deise. Da gênese aos compromissos: uma história da UERJ (1950-1978). Rio de Janeiro: EdUERJ, 1996.

MOTTA, Rodrigo Patto Sá. As universidades e o regime militar. Rio de Janeiro: Zahar, 2014.

A modernização autoritário-conservadora nas universidades e a influência da cultura política. In: REIS, Daniel Aarão; RIDENTI, Marcelo; MOTTA, Rodrigo Patto Sá (Org.). A ditadura que mudou o Brasil: 50 anos do golpe de 1964. Rio de Janeiro: Zahar, 2014a.

PARDAL, Paulo. UERJ: apontamentos sobre sua origem no $40^{\circ}$ aniversário de fundação e 60 de ensino. Rio de Janeiro: UERJ, 1990.

PEREZ, Maurício Dominguez. Estado da Guanabara: gestão e estrutura administrativa do governo Carlos Lacerda. Tese (Doutorado em História Social) - UFRJ, Rio de Janeiro, RJ, 2005. 
POLÍCIA LIBERTA O LÍDER DE FAVELADOS. Correio da Manhã, Rio de Janeiro, p. 2, 16 dez. 1964.

POLLAK, Michael. Memória, esquecimento, silêncio. Estudos Históricos, Rio de Janeiro, v. 2, n. 3, p. 3-15, 1989.

PRONTA EM três anos a cidade universitária da UEG. Correio da Manhä, Rio de Janeiro, p. 4, 17 ago. 1968.

RAMADON, Luis Fernando. UERJ: Uma história apaixonante. Accamitas, 2017. Disponível em: <http://www.accamtas.com.br/2017/01/uerj-uma-historia-apaixonante. html>. Acesso em: 26 jun. 2020.

ROTHEN, José Carlos. Os bastidores da Reforma Universitária de 1968. Educação e Sociedade, Campinas: v. 29, n. 103, p. 453-475, mai./ago. 2008.

SILVA, Eliazar João da. A seleçáo brasileira de futebol nos jogos da Copa do Mundo entre 1930 e 1958: o esporte como um dos símbolos da identidade nacional. Tese (Doutorado em História) - UNESP, Assis, SP, 2004.

UEG - UNIVERSIDADE DO ESTADO DA GUANABARA. Boletim da UEG. Sessão do dia 1 de outubro de 1962. Rio de Janeiro, 1 nov. 1962a. p. 10

p. 10.

Boletim da UEG. Sessão do dia 6 de agosto de 1962. Rio de Janeiro, 1 set.1962b.

Plano de Reestruturação da UEG (Subsídios). Rio de Janeiro: UEG, 1965.

VOLDMAN, Danièle. Definiçôes e usos. In: FERREIRA, Marieta de Moraes; AMADO, Janaína. Usos e abusos da História Oral. Rio de Janeiro: Editora FGV, 2015.

\section{Fontes orais}

CUNHA, Haroldo Lisboa. [set. 1980]. Entrevistador: Nei Barbosa. Depoimento concedido ao programa Memória UERJ do Centro de Tecnologia Educacional da UERJ. Rio de Janeiro, RJ, 30 set. 1980.

LYRA FILHO, João. [out. 1980]. Entrevistador: Nei Barbosa. Depoimento concedido ao programa Memória UERJ do Centro de Tecnologia Educacional da UERJ. Rio de Janeiro, RJ, 6 out. 1980. 
Resumo: O presente artigo parte dos depoimentos de dois ex-reitores da Universidade do Estado do Rio de Janeiro (UERJ) nas décadas de 1960 e 1970, Haroldo Lisboa da Cunha e João Lyra Filho, para analisar o processo de consolidação e expansão da instituição no período, incluindo a construção do campus do Maracanã e a reorganização interna de acordo com os princípios da Reforma Universitária de 1968. Os depoimentos, os primeiros tomados pelo programa Memória UERJ, em 1980, permitem compreender as visóes dos ex-reitores sobre suas açóes, as ideias que os motivaram e os conflitos e alianças estabelecidos com o campo político da cidade do Rio de Janeiro e do Brasil.

Palavras-chave: UERJ. História Oral. Reforma universitária. Ditadura civil-militar.

\title{
How a university is built: the trajectory of UERJ in the view of his rectors
}

\begin{abstract}
This article starts from the statements of two former rectors of the Rio de Janeiro State University (UERJ) in the 1960s and 1970s, Haroldo Lisboa da Cunha and Joâo Lyra Filho, to analyze the process of consolidation and expansion of the institution in the period, including the construction of the Maracanã campus and the internal reorganization according to the principles of the University Reform of 1968. The statements, the first taken by the Memory UERJ program, in 1980, allow us to understand the views of the former rectors about their actions, the ideas that motivated them and the conflicts and alliances established with the political arena on Rio de Janeiro and Brazil.
\end{abstract}

Keywords: UERJ. Oral History. University reform. Civil-military dictatorship.

Recebido em 29/03/20

Aprovado em 25/05/20 